\title{
Correction to: Fedor Krause (1857-1937): the father of neurosurgery
}

\section{Susanna Bacigaluppi ${ }^{1}$ (D) Nicola Luigi Bragazzi ${ }^{2,3} \cdot$ Mariano Martini $^{2}$}

Published online: 20 February 2020

(C) Springer-Verlag GmbH Germany, part of Springer Nature 2020

\section{Correction to: Neurosurgical Review}

https://doi.org/10.1007/s10143-019-01186-1

The original version of this article contained errors in the caption of fig. 3 .

It was corrected in the following way: Fig. 3a) "retrosigmoid approach" to "wide retrosigmoid approach"; Fig. 3b) citation [1] replaced by citation [8]; Fig. 3c) "Subtemporal approach" to "Subtemporal extradural approach".

The original article has been corrected

The online version of the original article can be found at https://doi.org/ 10.1007/s10143-019-01186-1

Susanna Bacigaluppi

susannabacigaluppi@yahoo.it

1 Department of Neurosurgery, E.O. Ospedali Galliera, Genoa, Italy

2 Section of History of Medicine and Ethics, Department of Health Sciences (DISSAL), University of Genoa, Genoa, Italy

3 School of Public Health, Department of Health Sciences (DISSAL), University of Genoa, Genoa, Italy 